\title{
Automatic Rule-Based Checking for the Approval of Building Architectural Designs of Airport Passenger Terminals based on BIM
}

\author{
Ítalo Guedes ${ }^{1}$, Max Andrade ${ }^{2}$ \\ ${ }_{1,2}^{1}$ Universidade Federal de Pernambuco \\ ${ }^{1}$ italo_guedes_@hotmail.com²max.andrade@ufpe.br
}

In Brazil, the evaluation processes of building architectural designs of Airports Passenger Terminal (PT) are carried out manually. It depends on the architects' knowledge, leading to possible errors. On the other hand, the rule checking in BIM-modeled building projects opens up new horizons for this type of activity. Based on Code Checking concepts, this paper presents a method for automating rule checking for building code in building architectural design of PT. Following the aspects of Design Science Research, it is developed in two stages: Construction (theoretical foundation, creating rule checking for the PT, implementation of the rules in BIM softwares for code checking and validation) and Evaluation of artefact. This paper shows a series of problems resulting from the evaluation of PT using traditional methods. It can be concluded that the use of rules for regulatory code checking with BIM allows standardization in the evaluation of architectural design of $P T$.

Keywords: Code Checking, Passenger Terminal, Building Information Modeling, Rule checking

\section{INTRODUCTION}

Building Architectural Design of Airports Passenger Terminal (PT), by this nature, is complex, considering the series of prerequisites to be met. Those prerequisites cover not only architectural programming and form-finding, traditionally related to the architecture design, but also operational constraints, such as service levels, passenger flow (loading and unloading), operational activities (airlines, auxiliary companies, and public agencies), and operational processing for passengers.

In Brazil, the evaluation processes of building architectural designs of PT are carried out manually.
That depends exclusively on the architects' knowledge; they work as analysts, validating the processes based on empirical knowledge. Such method tends to be time-consuming in view of the complexity of the design projects. In addition, each analyst may request different design adjustments based on their knowledge, providing margins for possible errors such as lack of standardization

On the other hand, the rule checking in BIMmodeled building projects opens up new horizons for this type of activity. That is due to the fact that, once the building is modeled, it is possible to perform the automatic evaluation of the building project 
through the data available in the 3D model. This procedure is recognized as Code Checking.

Until the pre-BIM era, the conception and development of building architectural design was accomplished through a mental exercise that spawned various spatial conceptions and evaluated them intuitively, based on the designer's knowledge and accumulated experience (EASTMAN, 2009). With the technologies that support BIM, specifically interoperability and parametric modeling, it is possible to verify that the building model (virtual prototype of the building presented by the architect) has correct objects, conventions, proportions and other structures necessary for complete evaluation.

Based on these concepts, this research aims to propose and to experiment a method for automating rule checking for building code in building architectural design of PT. The objective of the method is to improve and increase the evaluation capacity performed by PT architectural design analysts as well as to benefit management by the public agency responsible for such activities. Demonstrating the potential of BIM for the evaluation design processes of PT is one of the results expected. This type of evaluation is already a reality in some countries such as the US (GSA), Singapore (CORELNET - Construction and Real Estate NETwork), and Norway (HITOS)

Benning et al. (2010) classify automatic detection based on interference rules in two categories: clash detection and code checking interferences. According to those authors, the first type consists of the cross-checking process between the specialties for the discovery of cross between 3D geometric elements. As for the second one, it refers to the detection of code-based interferences to validate compliance with standards regulations and requirements in general. This research analyzes the application of automatic detection for code checking interferences.

\section{METHOD}

From the methodological point of view, the present work is based on the Design Science Research, which, according to March and Smith (1995),consists of two macro stages. The first stage is Construction, phase of development of the artifacts. In this research, it is represented by a construction of a specialized method for rule checking, based on regulatory code verification in order to prove it to be a solution to the proposed problem (step in development in this research). The second stage is Evaluation of the artifact, by measuring the efficiency of the artifact through the behavior verification in its environment or context (this step is still to be developed).

The Construction stage consists of three phases. The first phase consisted in the theoretical foundation on the subject. This research began with a Systematic Review of Literature (SRL). International and national publications on the subject have been identified in the last 10 years. Case studies were then carried out in the processes of analysis and validation of PT architectural designs in Brazil, with the collaboration of INFRAERO (Brazilian federal public company responsible for the administration of the country's main airports as well as for the evaluation of airport building designs). The second phase, still under development, consists in creating rule checking for the PT architectural designs based on Brazilian legislation (INFRAERO Criterion and Conditioning Manual for Airport Planning - INFRAERO, 2006). The objective of this step was to translate the main Brazilian standards into criteria that can be inserted in automatic evaluation software based on BIM. The next step, also in development, is the implementation of the rules in BIM evaluation and quantification softwares, for code checking and validation (Succar, 2015). Based on some software testing and literature experiences, which point to a more systematic use of the Solibri Model Checker (SMC) in places such as Singapore (Corenet), Norway (Stasbygg), Australia (CRC), and the USA (ICC and GSA ) (Eastman et al., 2009), we chose to carry out the experiments using this software. Once the software has been defined, the checking rules in SMC are being created and tested in a Brazilian architectural design of PT modeled on BIM tool. Finally, the third phase consists of the creation and formatting of reports, which 
Figure 1 Implementation Process proposed by this research (Code Checking) must be generated in an automated way by the system to assist analysts in the evaluation of PT architectural design.

The analysis is not only for what types of rule requirement can be implemented and how to implement them in BIM evaluation software, but also for how the model should be built by the designers so as to be able to be accurately evaluated in BIM softwares. In this phase is for the analysis of the characteristics that need to be incorporated in the BIM models (for example, standardization in the space's name) to be correctly evaluated in the SMC, and of the terminologies for the rules types as well as their classification using a publicly available open standard; for this paper, it is based on the Industry Foundation Classes (IFC) format. The IFC has been accepted as the only open and relatively mature standard currently supported by leading BIM applications.

The Figure 1 (below) describes the artifact implementation process map proposed by this research. The stages were constituted by the following phases: a) Diagnosis / Implementation: identification of the existing rules as well as classification, interpretation, and validation of the rules that may or may not be implemented; b) Software configuration: validation of the model exported via (.ifc), pre-configuration of the rules in the evaluation software, and definition of guidelines for modeling (i.e. the architectural design offices must hang the information in the BIM model so that it can be used in the evaluation process); c) Automatic verification: automatic evaluation in the BIM model is performed based on the preestablished parameters and the automatic verification report (results) is generated through the evaluation software.

After creating and testing the artifact, the next step is to experiment the artifact in a Brazilian PT pilot design project. To do so, the design team developing the pilot design project will be training on how to model, following the prescriptions to be proposed by this work. Then, the last step will be to enable the team of analysts to use the proposed eval- uation method, to follow the evaluation process and creation of reports, as well as to analyze the method efficiency compared to the traditional processes used by INFRAERO.

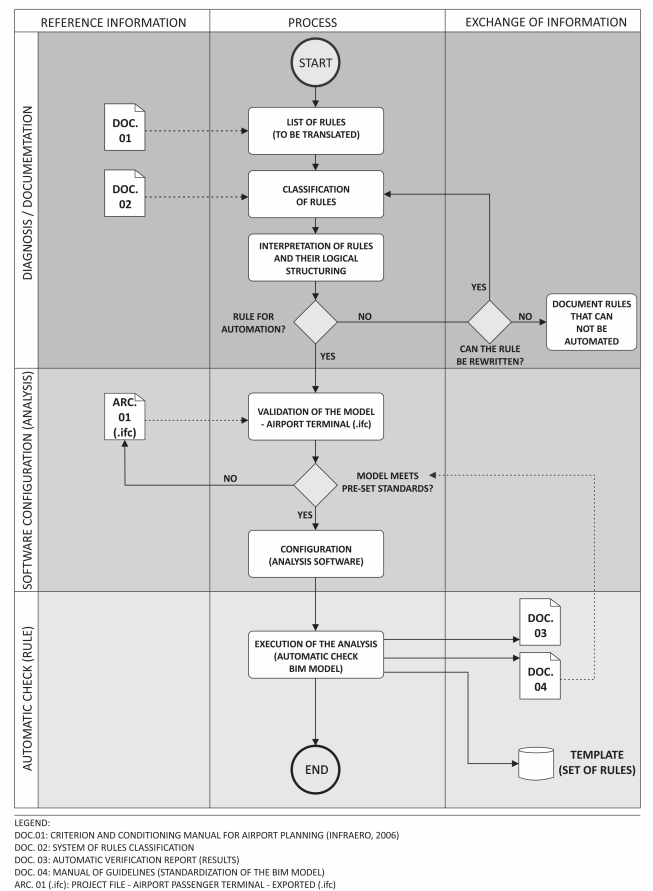

\section{RESULTS}

The initial studies show a series of problems resulting from the evaluation of PT using traditional methods. The method proposed in this work is also presented and discussed. Some of the simulations indicate, albeit in a preliminary way, the feasibility of using the automatic BIM rule checking for the approval of PT architectural designs in Brazil.

From the case studies carried out with the evaluation team of architectural designs of PT, it was possible to identify that: the quality of the evaluation of PT architectural design is directly associated to the level 
of the analysts' knowledge; design evaluations take place over long periods due to the complexity of the project (in some cases, it may exceed one year); there is ambiguity in the analysis of the design project by analysts (they often interpret the criteria in a subjective way); and lack of standardization for evaluations, that is, certain criteria are disregarded in one analysis but considered in others.

On the other hand, from the analysis of the Criteria and Conditioning Manual for Airport Planning (Annex 2), it was possible to identify a series of categories for possible components and their respective parameters that can be translated into rules checking of regulatory code for the PT architectural designs. These were grouped into 6 categories and have 119 components that can be implemented in an automatic BIM rule checking process (Figure 2 ).

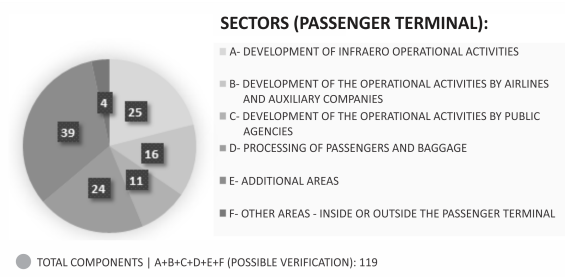

The current stage of this work is the creation of automatic evaluation rules for each of those components identified in Figure 2. For each component, a rule is created and its degree of complexity in the evaluation activity is analyzed from the design project. Creating the rules will make it possible to test, one by one, and identify those suitable for implementation as well as those that are complex, imprecise and can hamper the PT modeling and evaluation stage. Finally, the list of rules (based on the Criterion and Conditioning Manual for Airport Planning) proposed by this research will be presented and the evaluation method of PT will be described. Each rule studied is also classified according to the four general classes of rules proposed by Solihin and Eastman (2015). It has been verified that the rules evaluated are predominantly classified as Class 2 (SOLIHIN; EASTMAN, 2015). This rule class, according to the aforementioned au- thors, requires derived attribute values based on a single value or a limited set of derived values, which makes the data-derived checking a simple activity.

For this paper, examples already implemented will be presented (Figures 3 and 4), which demonstrate how these components (contained in the Criteria and Conditioning Manual) can be translated into SMC rules to be automatically evaluated from a PT BIM model. In this experiment, two evaluations are presented (Tables 1 and 2): in condition 1, the component is not met and condition 2 meets the component established by the Design Criteria and Conditions Manual.

Table 1 describes the rule 01 (condition 1) presented in this paper. The acceptance condition of this rule is: width of the service circulation between check-in queues and check-in service counters should be less than or equal to $3.00 \mathrm{~m}$. If this rule is met, this component is valid; if it is not, the designer needs to review the design project, which will need a re-evaluation. Figure 3 shows the evaluation of the rule automatically generated in the SMC. For this case, the condition was not met and, therefore, the program identified the non-compliance with the established rule, with the need to change the PT architectural design.

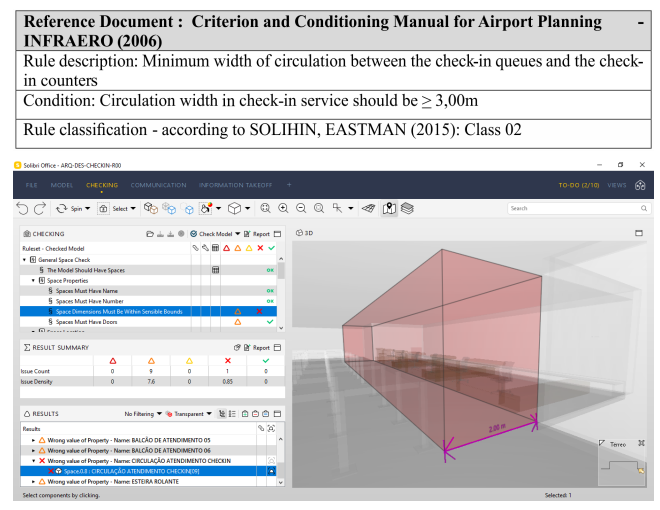

Table 2 describes the second rule presented in this paper. The acceptance condition is: length of queues reserved for the public to carry out the check-in
Figure 2

Sectors (Passenger

Terminal)

Table 1

Rule 01: Description verified on BIM

Model

Figure 3

View representing the

non-compliance

with rule 01 , automatically evaluated in SMC 
Table 2

Rule 02: Description verified on BIM

Model

Figure 4

View representing

the compliance

with rule 02 ,

automatically

evaluated in SMC should be bigger than $12.00 \mathrm{~m}$. If this rule is met, this component is valid; if it is not, the designer will need to revise the design, increasing the length of the queue to more than $12.00 \mathrm{~m}$. Figure 4 shows the evaluation of the rule automatically generated in the SMC. In this case, the established condition has been validated, which means that the designer does not need to change the design.

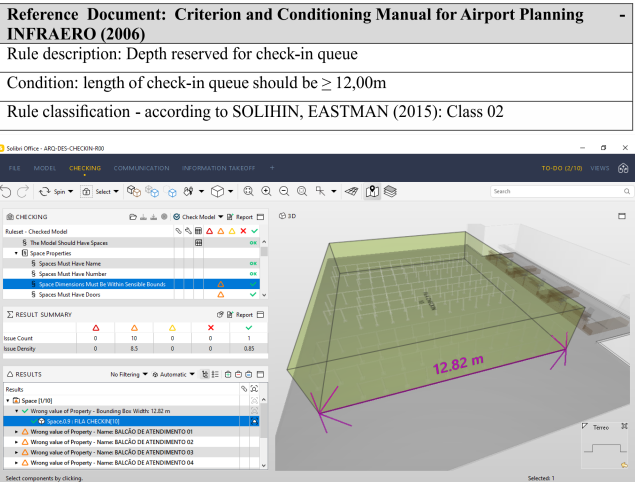

Although partially presented, these results show that the use of rules for regulatory code checking with BIM can allow standardization in evaluation of architectural design projects of Airport Passenger Terminals. Therefore, (1) the capacity of evaluation by design project analysts will increase and improve the management and assertiveness; (2) the evaluation time of this design category will decrease; and (3) analysts will have more time for the analysis of more complex issues related to the PT architectural design.

It is important to consider significant benefits should happen if rule checking can be organized generically, according to the type of checking software infrastructure, and not necessarily depending on the software being used. This abstract approach can allow a generic targeting of critical needs to the profile of software structures, benefiting the area of rule checking.

Throughout the creation of rules for checking, it was possible to observe the importance in potentializing the reuse of rules structures and conditions with standards. However, defining these patterns requires an understanding of software structures and an inductive reasoning. This has happened in the interpretation phase of the existing rules, by analyzing the rules, assumptions, dependencies, ambiguities, and exceptions that should be considered in the SMC implementation. The reuse of such standards significantly improves the extent of the set of rules to be implemented.

In addition, it is important to consider that both the investigation and the mapping of processes for the design project in a conventional way have allowed understanding the best practices, assisting in the definition of not well-defined rules.

Finally, it has been observed the need to create manuals for the construction of the models that take into account appropriate terminologies, compatible with the rules, as well as the classification of the model information, using a publicly available open standard, as IFC. Creating these defaults is crucial in developing any stable rule-checking application.

\section{DISCUSSIONS}

This research, although still under development, points to significant benefits in the use automated BIM rule checking in PT architectural design process, such as reducing time of analysis and validating architectural design as well as improving the assertiveness. In this context, this research proposes the creation of regulatory code checking in the SMC, from the codes and regulations, based on national standards, to develop design projects for this building category.

This design category is characterized by a typology defined by several sectors strategically distributed throughout the PT based on the INFRAERO Criterion and Conditioning Manual for Airport Planning (for example, Development of INFRAERO Operational Activities, Development of Operational Activities of Airline Companies and Auxiliary Companies). Due to this category profile, it is identified that the use of regulatory code checking rules (Solihim and 
Eastman - 2015) has a significant potential for design evaluation, bringing benefits for the design process.

Besides the Passenger Terminal, object of this work, it is possible to notice the potential for rule checking being applied in other areas of the airport site, considering that INFRAERO Criterion and Conditioning Manual establishes several possible parameters for the applicability of rules checking, both outside the Passenger Terminal (land side) as well as in the areas facing the aircraft courtyard (air side). Such fact allows the implementation of automatic rules checking for various components: public parking of vehicles (minimum number of parking spaces, based on passenger/year at the airport); ramp equipment (minimum area to support aircraft parked in the aircraft yard); lateral transition ramp (defined according to type of operation of the airport); supply fleet of PAA aircraft (minimum area of lots to house the set of facilities to fuels reserve at the airport, based on consumption $\left[\mathrm{m}^{3} /\right.$ month]); among other possible components for the implementation of automated BIM rule checking.

Another potential identified in this research is the use of the rule checking for validation of Level of Service (LOS) of airport terminals, based on parameters established by the IATA manual (International Air Transport Association, 2004). Thus, analysts are able to, through the rules checking in the BIM model, obtain automatic values regarding the quality and service conditions (LOS) offered by Brazilian airports, considering both the current scenario of the various built passenger terminals and future scenarios of possible renovation, as well as the construction of new airport passenger terminals to improve the quality of the offered services.

\section{REFERENCES}

ASHFORD, J. L. 1992, The Management of Quality in Construction, E\&F Spon, London

INTERNATIONAL AIR TRANSPORTATION ASSOCIATION, IATA 2004, 'Airport Development Reference Manual', in International Air Transport Association, IATA (eds) 2004, 9th Edition, IATA, London

CLAYTON, M., FUDGE, P. and THOMPSON, J. 2013 'Auto- mated plan review for building code complice using BIM', EG-ICE - Workshop, Vienna

EASTMAN, C., Jae-min, L., Yeon-suk, J. and Jin-kook, L. 2009, 'Automatic rule-based checking of building designs', Automation in Construction, v.18(8), pp. 1011-1033

EASTMAN, C, TEICHOLZ, P, SACKS, R and LISTON, K 2011 , BIM Handbook: A guide to Building Information Modeling for owners, managers, designers, engineers and contractors, Jonh Wiley $\backslash \&$ Sons, New Jersey

INFRAERO, C. 2006, 'Manual de Critérios e Condicionantes de Planejamento Aeroportuário', in Superintendência de Empreendimentos de Engenharia, Gerência de Planejamento de Engenharia (eds) 2006, Manual INFRAERO, INFRAERO, RIO DE JANEIRO

KEHL, C. and ISATTO, E.L. 2015 'Barreiras e oportunidades para a verificação automática de regras da produção na fase de projeto com uso da tecnologia BIM', Proceedings of TIC 2015, Recife, pp. 13-26

KHEMLANI, L 2005, 'CORELNET e-PlanCheck: Singapore', AECbytes, october 2005, p. Online

AIB MAINARDI, NETO and SANTOS, ET 2015 'Verificação de Regras em Modelos BIM: Um estudo de caso sobre projeto de arquitetura de estações ferroviárias', Proceedings of TIC 2015, Recife

MARCH, ST and SMITH, GF 1995, 'Design and natural science research in Information Technology', Decision Suport Systems, 15, pp. 251-266

IVO MAINARDI NETO, ANTÔNIO 2016, Verificação de regras para aprovação de projetos de arquitetura em BIM para estações de metrô, Master's Thesis, USP

RUSCHEL, R., VALENTE, C., CACERE, E. and QUEIROZ, S. R. 2013, 'O papel das ferramentas BIM de integração e compartilhamento no processo na indústria da construção civil', REEC - Revista Eletrônica de Engenharia Civil, 7, pp. 36-54

SOLIHIN, W and EASTMAN, C 2015, 'Classification of rules for automated BIM rule checking development', $A u$ tomation in Construction, 53, pp. 69-82

TOBIN, J. 2008, 'actomicBIM: Spliting Data to Unleash BIM', AEC Bytes, Building the Future, October 2018, p. Online 